\title{
Upregulation of microRNA-650 by PBX1 is correlated with the development of Helicobacter pylori-associated gastric carcinoma
}

\author{
Junzheng LIU ${ }^{1, *}$, Lei WANG ${ }^{2, *}$, Jie $\mathrm{LI}^{3}$, Yu XU ${ }^{4, *}$ \\ ${ }^{1}$ Digestive System Department, Cangzhou People's Hospital, Canghzou, Hebei, China; ${ }^{2}$ Department of General Surgery, Eastern Hospital of the \\ Second Hospital of Hebei Medical University, Shijiazhuang, Hebei, China; ${ }^{3}$ Medical Department, Dongying Second People's Hospital, Dongy- \\ ing, Shandong, China; ${ }^{4}$ Department of Oncology, Zibo Hospital of Traditional Chinese Medicine, Shandong University of Traditional Chinese \\ Medicine, Zibo, Shandong, China
}

${ }^{*}$ Correspondence: xuyu4241@163.com

${ }^{\#}$ Contributed equally to this work.

Received August 6, 2020 / Accepted October 5, 2020

\begin{abstract}
Helicobacter pylori (HP) infection induces the development of gastric carcinoma (GC), one of the most frequent and fatal cancers worldwide, via a progressive cascade. The roles of microRNAs (miRNAs) involved in the cascade and the behind mechanisms, however, are still unclear. This study was designed to investigate the expression of miR-650, a well-recognized oncogenic miRNA in GC samples and to analyze the associations between this miRNA and HP infection, and the molecular mechanism. Following miRNA- and mRNA-based microarray analyses, miR-650, pre-B-cell leukemia transcription factor 1 (PBX1), and LATS2 were filtered as targets. After that, function assays were implemented to assess their function in GC cells. miR-650 was upregulated in HP+ tissues and cells, and inhibition of miR-650 attenuated cell proliferation, invasion, migration, yet enhanced apoptosis. PBX1 was overexpressed in HP+ tissues and cells and promoted miR-650 transcription. Overexpression of PBX1 abrogated the effect of the miR-650 inhibitor on GC cells. miR-650 targeted LATS2, and LATS2 was poorly expressed in HP+ tissues and cell lines. Simultaneous knockdown of miR-650 and LATS2 reduced GC cell apoptosis. These results display that upregulation of miR-650 induced by HP infection and PBX1 dampens LATS2 in GC cells, potentially offering novel intervention targets for GC.
\end{abstract}

Key words: Helicobacter pylori, microRNA-650, gastric carcinoma, PBX1, LATS2

Gastric carcinoma (GC) accounted for more than 1,000,000 new cases in 2018 and an estimated 783,000 deaths (1 in every 12 deaths globally), making it the fifth most frequently diagnosed malignancy and the third major cause of cancerassociated death [1]. The mainstay of GC treatment remains curative resection but it has been shown that perioperative therapies could promote the survival of $10-15 \%$ for patients with locally advanced GC [2]. GC, a heterogeneous disease, includes three distinct subtypes: distal intestinal-type GC that relates to chronic gastritis and Helicobacter pylori (HP) infection; proximal intestinal-type gastroesophageal malignancies as well as diffuse signet-ring cell type malignancies [3]. Worldwide, about 660,000 cases of cancer in 2008 were attributable to $\mathrm{HP}$, corresponding to $32.4 \%$ of the 2 million cancer cases resulted from infectious agents [4]. Nevertheless, the mechanism into the correlation of HP with the GC progression has not been clearly established and needs to be elucidated.
microRNAs (miRNA) are non-coding 18-25 nucleotidelong RNA molecules that have the potency to modulate gene expression by inhibiting mRNA translation and stability, usually via complementary base pairing to their 3' untranslated region [5]. Intriguingly, an in vitro infection model was established by Matsushima et al. to monitor the modulation of miRNAs in the gastric epithelium in response to HP and unraveled the expression profiles [6]. A similar miRNA profiling performed by Lario et al. in duodenal ulcer disease induced by HP disclosed that miR-650 overexpression was specific to chronic-active gastritis [7]. Moreover, miR-650 was overexpressed in GC, which stimulated the proliferation and growth of cancer cells [8]. Overexpression of miR-650 was also indicated in prostate cancer samples and cells [9]. These existing reports made us connect the miR-650 expression with HP infection or GC development. In addition, upregulated transcription factor pre-B-cell leukemia transcription factor 1 (PBX1) was found in the gastric mucosa of GC 
patients relative to the healthy volunteers [10]. Given the possible pathogenesis of GC, deregulated miRNA expression caused by HP infection might lead to the bacteria-host interactions. However, the specific role and underlying mechanisms of the possible involved miRNA in GCs caused by HP infection remain largely unknown. In addition, large tumor suppressor kinase 2 (LATS2) was established as a direct target of miR-650 in non-small cell lung cancer cells [11]. In the present study, we evaluated the tumorigenic role of miR-650 in $\mathrm{HP}^{+} \mathrm{GC}$ with the involvement of a transcription factor PBX1 and the downstream LATS2, as well as its biological functions and molecular mechanisms using in vitro models.

\section{Patients and methods}

Patients and sample collection. From January 2014 to January 2017, 119 patients who underwent curative resection at the Cangzhou People's Hospital were collected, 73 of those were $\mathrm{HP}^{+}$and 46 were $\mathrm{HP}^{-}$. A rapid urease positive test was performed to determine whether the patient was $\mathrm{HP}^{+}$. All specimens were confirmed to be GC by the histopathology. The patient population comprised of 81 males and 38 females with a mean age of $52.08 \pm 14.73$ years. There were 42 cases of high differentiation, 77 cases of poor differentiation, 57 cases with lymph node metastasis, 62 cases without metastasis. The GC patients were classified according to the clinical tumor, node, metastases stages, including 46 cases at the I-II stage and 73 cases at the III-IV stage. All patients had no history of any other tumors, and no chemotherapy or radiotherapy was performed before surgery. Fresh GC samples were instantly frozen in liquid nitrogen after the surgical resection and kept at $-80^{\circ} \mathrm{C}$. Ethically, the samples were harvested following the guidelines issued by the Ethics Committee of Cangzhou People's Hospital, following the Declaration of Helsinki. Moreover, informed consent was collected from all studied individuals.

Microarray analyses. Three $\mathrm{HP}^{+}$and $\mathrm{HP}^{-} \mathrm{GC}$ tissues were homogenized for RNA extraction using TRIzol (Thermo Fisher Scientific Inc., Waltham, MA, USA). RNA purity was detected by NanoDrop 2000C (Thermo Fisher). The total RNA $(50 \mu \mathrm{g})$ was purified using the Taqman miRNA ABC purification kit (Thermo Fisher) and labeled using miRNA Complete Labeling and Hyb Kit (Agilent Technologies) for the collected miRNA. mRNA was not labeled. miRNA was hybridized with Human miRNA Microarray Release 14.0 (Agilent) and mRNA with SurePrint G3Human Gene Expression v3 (Agilent). The hybridized microarray was placed in the SureScan Dx Microarray Scanner for scanning (Agilent), and the genes with $\mid \log 2$ FoldChange $\mid>1.5$ and $p<0.01$ were selected for plotting the heatmaps.

Reverse transcription quantitative PCR (RT-qPCR). Total RNA was isolated from cell and tissue specimens using TRIzol reagents and complementary DNA (cDNA) was produced following the manufacturer's protocol using a Reverse Transcription kit (Takara Holdings Inc., Kyoto,
Japan). Quantification was conducted on a Bio-Rad CFX96 ${ }^{\text {tw }}$ Real-Time PCR System (Bio-Rad, Inc., Hercules, CA, USA) using the SYBR Green PCR Kit (Takara). Primers for miR-650, PBX1, LATS2, and miRNA internal reference U6, and mRNA internal reference glyceraldehyde 3-phosphate dehydrogenase (GAPDH) were synthesized by Sangon (Shanghai, China) (Table 1). Gene expression was calculated by the $2^{-\Delta \Delta C t}$ method.

Flow cytometric analysis. The cells were detached with $0.25 \%$ trypsin, centrifuged, and resuspended to obtain a single cell suspension with $1 \times 10^{6} \mathrm{cell} / \mathrm{s} / \mathrm{ml}$. Single cell suspension $(100 \mu \mathrm{l})$ was seeded onto 6-well plates and treated with $10 \mathrm{mg} / \mathrm{ml}$ propidium iodide (PI, Sigma-Aldrich) at ambient temperature to avoid light exposure for $20 \mathrm{~min}$. Afterward, 10 $\mathrm{mg} / \mathrm{ml}$ Annexin $\mathrm{V}$ was added for another $10 \mathrm{~min}$ incubation in the dark. The cells were then loaded onto a flow cytometer (BD Biosciences, San Jose, CA, USA) following adding 400 $\mu \mathrm{l}$ staining buffer at $4{ }^{\circ} \mathrm{C}$. PI and Annexin $\mathrm{V}$ double-positive cells were regarded as apoptotic cells and analyzed using Cell Quest software.

Cell treatment. Human GC HGC-27 and MKN-45 cells, as well as human embryonic kidney 293T (HEK293T) cells, were from ATCC (Manassas, VA, USA). The cells were cultured in RPMI-1640 medium (Hyclone) containing 10\% inactivated FBS (Thermo Fisher), $100 \mathrm{U} / \mathrm{ml}$ penicillin/streptomycin (Thermo Fisher) with a constant temperature of $37^{\circ} \mathrm{C}$ and $5 \% \mathrm{CO}_{2}$. Standard strain HP $26695\left(\mathrm{CagA}^{+}\right)$was provided by the Chinese Center for Disease Control and Prevention (Beijing, China). After cells reached an $80 \%$ confluence, the cells were infected with $\mathrm{HP}$ at a multiplicity of infection of $100: 1$ and cultured under $37^{\circ} \mathrm{C}$ microoxygenophilic conditions $\left(5 \% \mathrm{O}_{2}, 10 \% \mathrm{CO}_{2}\right.$, and $\left.85 \% \mathrm{~N}_{2}\right)$ [12]. GC cells infected with HP were incubated for $12 \mathrm{~h}$ and collected as $\mathrm{HP}^{+}$cells. GC cells cultured with dimethyl sulfoxide under the same condition were regarded as the $\mathrm{HP}^{-}$group.

Cell transfection. $\mathrm{HP}^{+} \mathrm{HGC}-27$ and $\mathrm{MKN}-45$ cells were transfected with miR-650 control, miR-650 inhibitor, PBX1-negative control (NC), PBX1-overexpression (OE),

Table 1. Sequences of the RT-qPCR primers.

\begin{tabular}{|c|c|}
\hline Gene name & Primer \\
\hline \multirow{2}{*}{ miR-650 } & Forward: 5'-AGAGGAGGCAGCGCTCT-3' \\
\hline & Reverse: 5’-CAGTGCGTGTCGTGGAGT-3’' \\
\hline \multirow{2}{*}{ PBX1 } & Forward: 5'-GGAGGGTTTCTCTCCCAACG-3' \\
\hline & Reverse: 5'-GGGAGTCTAGGACAGAGGCA-3' \\
\hline \multirow{2}{*}{ LATS2 } & Forward: 5'-AAGACTTTTCCTGCCACGAC-3' \\
\hline & Reverse: 5’-TCATTAGCAAAAGGCAACAA-3' \\
\hline \multirow{2}{*}{ U6 } & Forward: 5'-GCTTCGGCAGCACATATACTAAAAT-3' \\
\hline & Reverse: 5’CGCTTCACGAATTTGCGTGTCAT-3’' \\
\hline \multirow{2}{*}{ GAPDH } & Forward: 5’-CTGGGCTACACTGAGCACC-3’' \\
\hline & Reverse: 5'-AAGTGGTCGTTGAGGGCAATG-3' \\
\hline
\end{tabular}

Abbreviations: miR-microRNA; PBX1-pre-B-cell leukemia transcription factor 1; LATS2-large tumor suppressor kinase 2 gene; RT-qPCR-reverse transcription quantitative PCR; GAPDH-glyceraldehyde 3-phosphate dehydrogenase 
miR-650 inhibitor+PBX1-NC, miR-650 inhibitor+PBX1OE, LATS2-NC, small interfering RNA (si)-LATS2, miR-650 inhibitor+LATS2-NC, or miR-650 inhibitor+si-LATS2. miR-650 inhibitor, PBX1-OE, si-LATS2, and their control were produced by GenePharma (Shanghai, China). The cells were plated on a 24 -well plate and grown until $70-80 \%$ confluence for transfection using a Lipofectamine 2000 kit (Thermo Fisher). miR-650 inhibitor, PBX1-OE, si-LATS2 and their controls were diluted in $250 \mu \mathrm{l}$ serum-free medium (50 nM), and $5 \mu$ l Lipofectamine was also diluted with $250 \mu \mathrm{l}$ serum-free medium. After incubation at ambient temperature for $5 \mathrm{~min}$, the two solutions were mixed and stored at ambient temperature for $20 \mathrm{~min}$. After incubation at $37^{\circ} \mathrm{C}$ with $5 \% \mathrm{CO}_{2}$ for $6 \mathrm{~h}$, the cells were cultured in a medium containing $10 \%$ FBS.

CCK-8 assay. The viability of HGC-27 and MKN-45 cells was detected by CCK-8 (Dojindo Molecular Technologies, Kumamoto, Japan) at $24 \mathrm{~h}$ post-transfection, and the cells were plated into 96-well plates. At the $0,24,48$, and $72 \mathrm{~h}$ of culture, $10 \mu \mathrm{CCCK}-8$ was added for a $5 \mathrm{~h}$ culture, and the OD value at $450 \mathrm{~nm}$ was evaluated to assess cell survival.

5-ethynyl-2'-deoxyuridine (EdU) labeling. The cell proliferation test was carried out using a CellLight EdU Apollo 567 in vitro imaging kit (Guangzhou RiboBio Co., Ltd., Guangzhou, Guangdong, China). The cells were transfected for $48 \mathrm{~h}$, seeded at $8 \times 10^{3}$ cells/well into 96 -well plate, and incubated with $50 \mathrm{~mol} / \mathrm{l} \mathrm{EdU}$ solution at $37^{\circ} \mathrm{C}$ for $2 \mathrm{~h}$. After a 30 min fixation with $4 \%$ paraformaldehyde, the cells were treated with $0.5 \%$ Triton X-100 for $0.5 \mathrm{~h}$, and with $100 \mathrm{ml}$ $1 \times$ Apollo reaction cocktail for $0.5 \mathrm{~h}$. Hoechst 33342 solution $(5 \mathrm{ml})$ was used for a $30 \mathrm{~min}$ nucleus staining. A fluorescence microscope (Olympus Optical Co., Ltd., Tokyo, Japan) was utilized to photograph and calculate the percentage of EdU positive cells to assess cell proliferation.

Transwell assay. Matrigel (Corning Glass Works, Corning, N.Y., USA) used in this study was dissolved overnight and diluted with DMEM (Solarbio, China) at 1:3 free of serum for chamber coating. Single cell suspension along with $0.2 \mathrm{ml}$ DMEM was uniformly plated in the upper chamber, while $0.5 \mathrm{ml}$ DMEM (with 10\% FBS) was added to the lower chamber. After a $48 \mathrm{~h}$ incubation, the cells remaining on the membrane in the upper chamber were removed with cotton swabs, while the cells that invaded through the membrane were fixed for $20 \mathrm{~min}$ in 5\% ethanol and stained with crystal violet solution for $10 \mathrm{~min}$. Five high-power visual fields were randomly selected for cell counting under an inverted microscope (Olympus) to observe cell invasion. For the migration assay, we performed the same procedures as described above except Matrigel coating.

Hoechst staining. The transfected HGC-27 and MKN-45 cells were suspended to $1 \times 10^{6}$ cells $/ \mathrm{ml}$ concentration. The cell suspension was cultured for 2 days, fixed with $4 \%$ paraformaldehyde for $20 \mathrm{~min}$, and stained with $0.5 \mathrm{ml}$ Hoechst 33258 solution (Solarbio) for $10 \mathrm{~min}$ (all at ambient temperature). Cells were added dropwise onto the slide, and the apoptosis was detected by observing the apoptotic nucleus using a fluorescence microscope (Olympus).

Wound healing assay. When cell confluence reached $90 \%$, cells were starved in a serum-free medium for 1 day. Then, a sterile pipette tip was used to scratch the confluent cells. After the floating cells were rinsed with phosphate-buffered saline (PBS), the serum-free medium was supplemented again for $1 \mathrm{~h}$ incubation. After the cells recovered from starvation, the width of the wound healing at $0 \mathrm{~h}$ and $48 \mathrm{~h}$ was recorded.

Chromatin immunoprecipitation (ChIP) assay. TransmiR v2.0 (http://www.cuilab.cn/transmir) was used to predict binding sites between miR-650 and PBX1. The stably grown cells were fixed at ambient temperature with $4 \%$ paraformaldehyde for $10 \mathrm{~min}$ and allowed to stand at ambient temperature with glycine $(0.125 \mathrm{M})$ for $5 \mathrm{~min}$. Afterward, the cells were collected in Eppendorf tubes after 2,000 rpm centrifugation for $5 \mathrm{~min}$, subjected to an ultrasonic treatment for $2 \mathrm{~h}$ with sodium dodecyl sulfate (SDS) lysis buffer and protease inhibitor complexes (Thermo Fisher Scientific), and centrifugation at $4^{\circ} \mathrm{C}$ at $13,000 \mathrm{rpm}$ for $5 \mathrm{~min}$. The cells were then probed with negative control rabbit antibody against IgG (ab109489, 1:100, Abcam, Cambridge, MA, USA) and mouse antibody against PBX1 (ab13537, 1:100, Abcam) overnight at $4{ }^{\circ} \mathrm{C}$ and reacted with Protein Agarose/Sepharose (Solarbio) for $30 \mathrm{~min}$ and centrifuged. PBS was applied to rinse the nonspecific complex. Crosslinking was reversed at $65^{\circ} \mathrm{C}$ overnight. The DNA fragments were purified by phenol/chloroform extraction, and RT-qPCR was then used to detect PBX1 enrichment.

Dual-luciferase experiment. GC cells were plated into 24 -well plates at $3 \times 10^{4}$ cells/well. After predicting the binding sites between miR-650 and LATS2 using starBase (http:// starbase.sysu.edu.cn/), LATS2 wild-type (WT) and mutant (MT) plasmids were constructed. The transient transfection of reporter plasmids was carried out with Lipofectamine 2000 transfection reagent (Thermo Fisher). The total RNA was extracted by TRIzol reagent after $48 \mathrm{~h}$. Luciferase activity was determined using a dual-luciferase reporter gene detection system (Promega, USA) and normalized with Renilla luciferase.

Western blot. The protein was isolated using radioimmunoprecipitation assay lysis buffer (Takara, Japan) after $48 \mathrm{~h}$ of incubation. The protein concentration was evaluated by the bicinchoninic acid method (Wuhan Boster Biological Technology Co., Ltd., Wuhan, Hubei, China). The extracted protein was heated at $95^{\circ} \mathrm{C}$ for $10 \mathrm{~min}$. Total protein $(30 \mu \mathrm{g})$ was resolved by $10 \%$ SDS-polyacrylamide gel electrophoresis and subsequently transferred to polyvinylidene fluoride membranes. The membranes were blocked in 5\% bovine serum albumin for $1 \mathrm{~h}$ and then probed with the following primary antibodies at $4{ }^{\circ} \mathrm{C}$ overnight: PBX1 (1:10000, ab192606, Abcam), LATS2 (1:200, ab110780), and $\beta$-actin (1:6000, ab6276), and with the secondary antibody (1:3000, ab205719) at $37^{\circ} \mathrm{C}$ for $1 \mathrm{~h}$. All antibodies were from Abcam. The membrane was developed via the exposure of chemi- 
luminescence reagent (Takara). The gray value of the target gene was analyzed by Image (National Institutes of Health, Bethesda, MD, USA) using $\beta$-actin as an internal control.

Statistical methods. Continuous variables between the two groups were analyzed by unpaired t-test. Differences among three or more groups were assessed by one-way or two-way analysis of variance (ANOVA) with comparisons between two groups using Tukey's post hoc test. The statistical analyses were carried out with SPSS22.0 (IBM SPSS Statistics, Chicago, IL, USA). Data are exhibited as mean \pm standard deviation (SD) from three assays. A p-value $<0.05$ was applied as the threshold for significance.
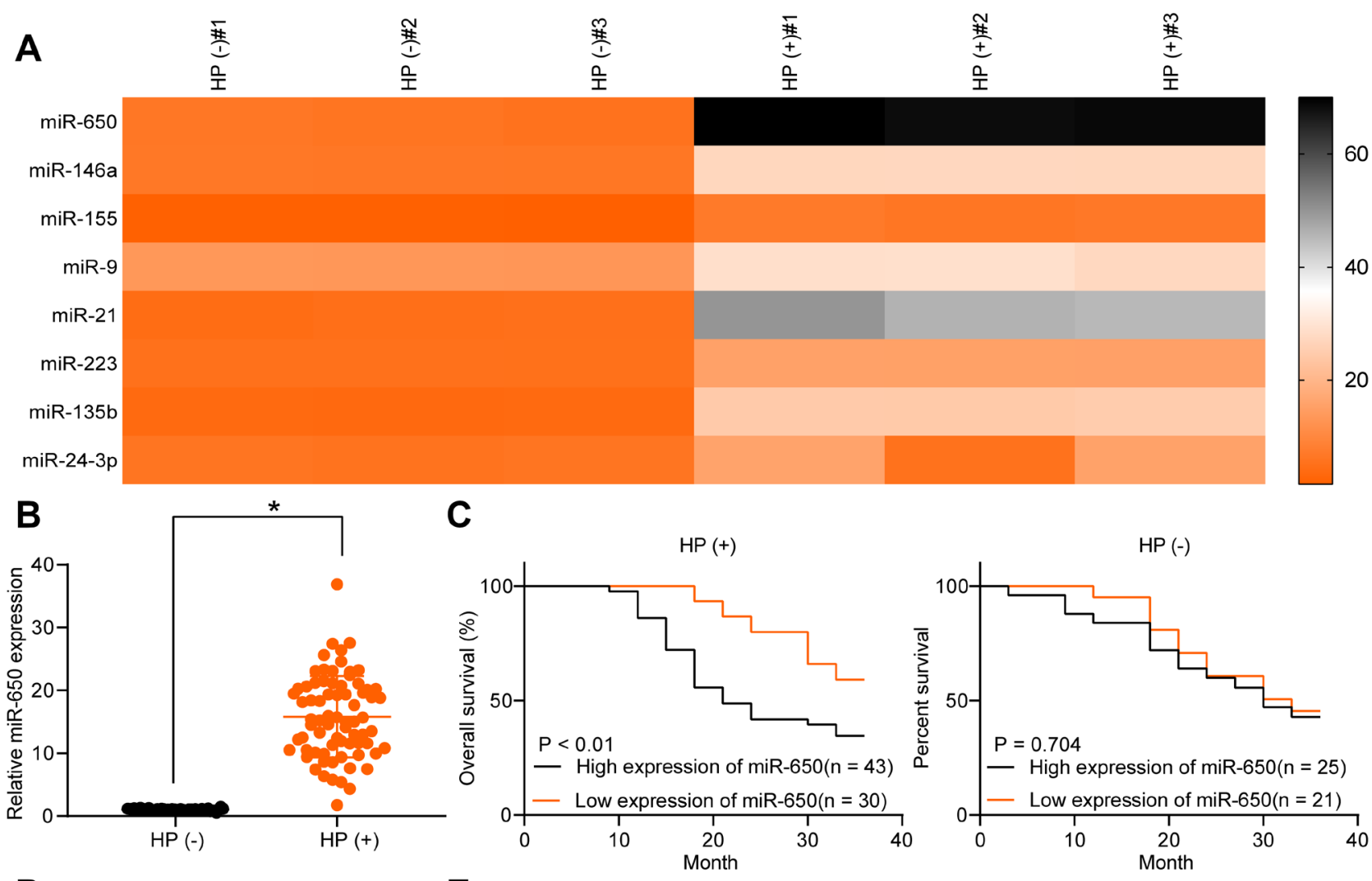

D

E
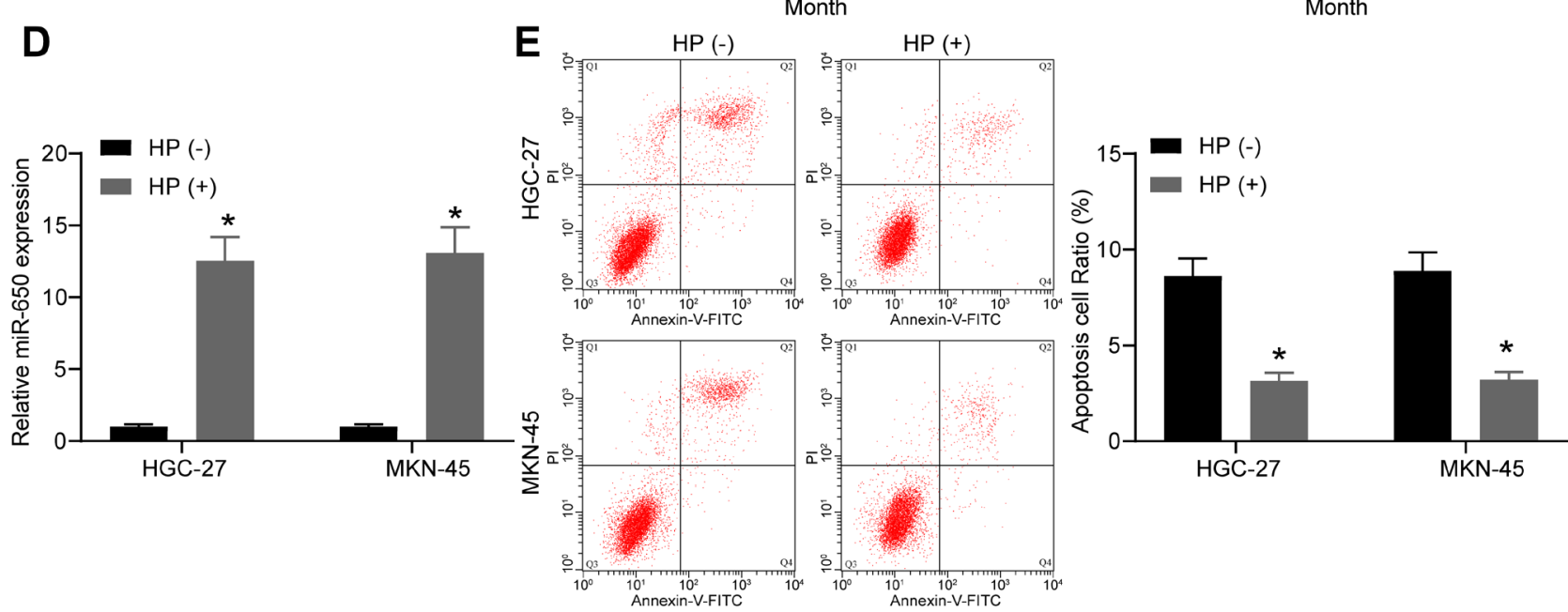

Figure 1. Effects of HP infection on miR-650 expression in GC cells. A) A microarray analysis of significantly upregulated miRNAs between $\mathrm{HP}^{+}$and HP- GC patients; B) RT-qPCR detection of miR-650 expression in tissues of $\mathrm{HP}^{+}$and $\mathrm{HP}^{-}$GC patients; C) prognostic analysis of patients with different expression of miR-650; D) RT-qPCR detection of miR-650 expression in HP ${ }^{+}$and HP- HGC-27 and MKN-45 cells; E) detection of HGC-27 and MKN-45 cell apoptosis after HP infection by flow cytometry. Continuous variables between the two groups were compared by unpaired t-test (panel B). Differences among three or more groups were tested by two-way ANOVA with comparisons between two groups using Tukey's post hoc test (panel $\mathrm{D}$ and $\mathrm{E}) .{ }^{*} \mathrm{p}<0.05$ vs. HP- GC tissues or cell lines. 


\section{Results}

miR-650 is increased significantly in $\mathrm{HP}^{+}$GC. After the GC patients were divided into $\mathrm{HP}^{+}$and $\mathrm{HP}^{-}$, three $\mathrm{HP}^{+}$ and $\mathrm{HP}^{-}$cancer tissue samples were selected for microarray analysis. Gene expression was normalized against the poorest expressed gene, miR-650, and a differential expression heatmap of the normalized genes was thus plotted. miR-650 expression increased significantly in cancer tissues of $\mathrm{HP}^{+}$patients, and the expression of miR-21 was also increased in the cancer tissues of $\mathrm{HP}^{+}$patients [13], but the difference in its expression was smaller than that of miR-650, so we chose miR-650 as our study subject (Figure 1A). We validated miR-650 expression trends (Figure 1B) by RT-qPCR. The survival rate of $\mathrm{HP}^{+}$patients with higher expression of miR-650 was much lower than that of patients with poorer expression of miR-650. While in the prognostic analysis of $\mathrm{HP}^{-}$patients, miR-650 expression differences had little effect on GC patients (Figure 1C). We then infected GC cells HGC-27 and MKN-45 with HP, and significantly higher miR-650 was observed in $\mathrm{HP}^{+}$cells than in $\mathrm{HP}^{-}$cells (before infection) (Figure 1D). Apoptosis detection at this time found a significant decline in the number of apoptotic
$\mathrm{HP}^{+}$cells (Figure 1E), which suggests that miR-650 might be an important oncogene for $\mathrm{HP}^{+} \mathrm{GC}$.

miR-650 downregulation inhibits proliferation and invasion of $\mathbf{H P}^{+} \mathrm{GC}$ cells. To test our hypothesis, the miR-650 inhibitor was delivered to detect cell changes. After confirming the successful transfection with RT-qPCR (Figure 2A), we performed the CCK-8 assays to examine GC cell proliferation. We observed cell viability within $0,24,48$, and $72 \mathrm{~h}$, and found that the proliferation of GC cells after miR-650 inhibitor transfection was decreased (Figure 2B). Meanwhile, we measured the DNA replication capacities of the cells by EdU labeling and found that the cell activity was reduced (Figure 2C) with the downregulation of the miR-650. We also detected the invasion of $\mathrm{HP}^{+} \mathrm{GC}$ cells by Transwell assays and noted that inhibition of miR-650 resulted in a significant decline in the number of invasive cells (Figure 2D). Therefore, we believe that the downregulation of miR-650 inhibits proliferation and invasion of $\mathrm{HP}^{+}$ GC cells.

miR-650 downregulation expedites apoptosis and reduces the migration of $\mathrm{HP}^{+}$GC cells. Using flow cytometry, it was observed that the apoptosis of GC cells was reduced after HP infection in the aforementioned experi-
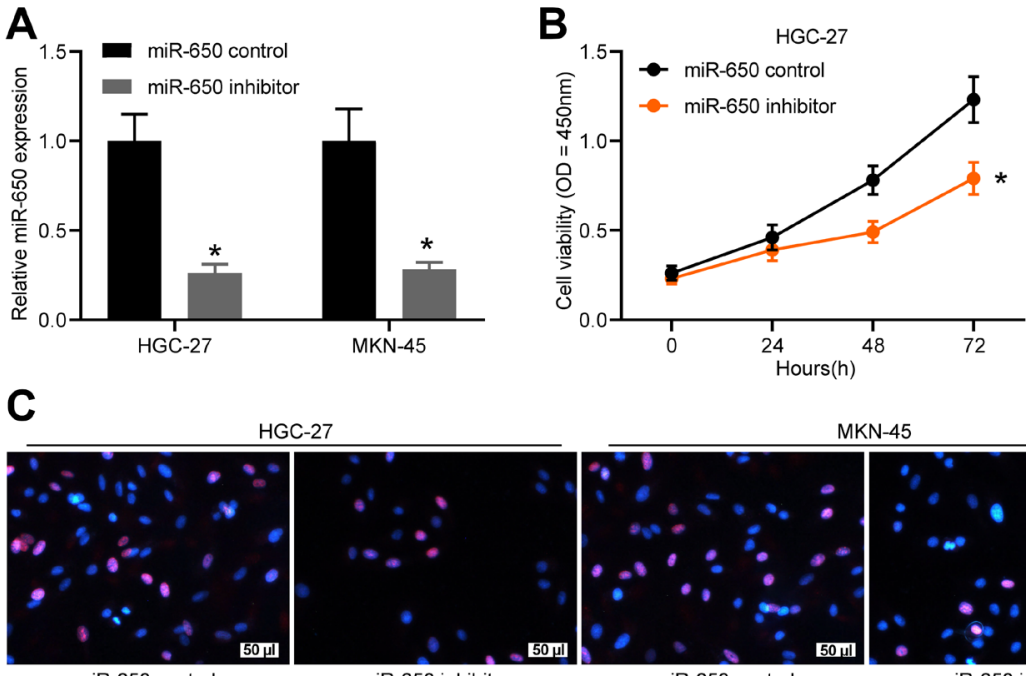

HGC-27

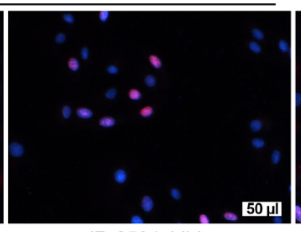

miR-650 control

miR-650 inhibitor

50ull

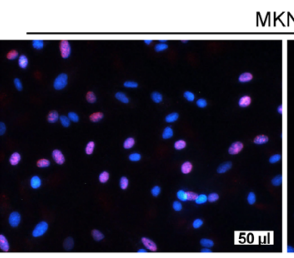

MKN-45

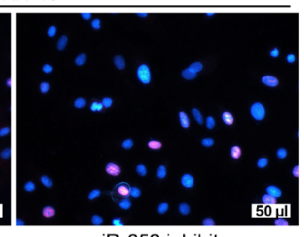

miR-650 inhibitor

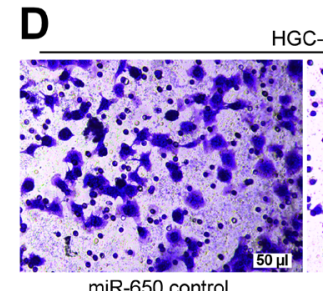

miR-650 control

HGC-27
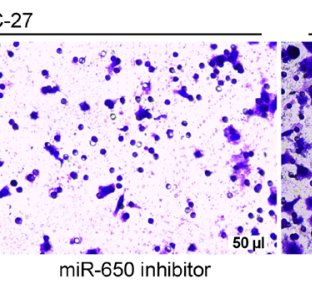

miR-650 contro

MKN-45

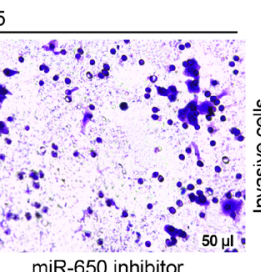

miR-650 control

miR-650 inhibitor
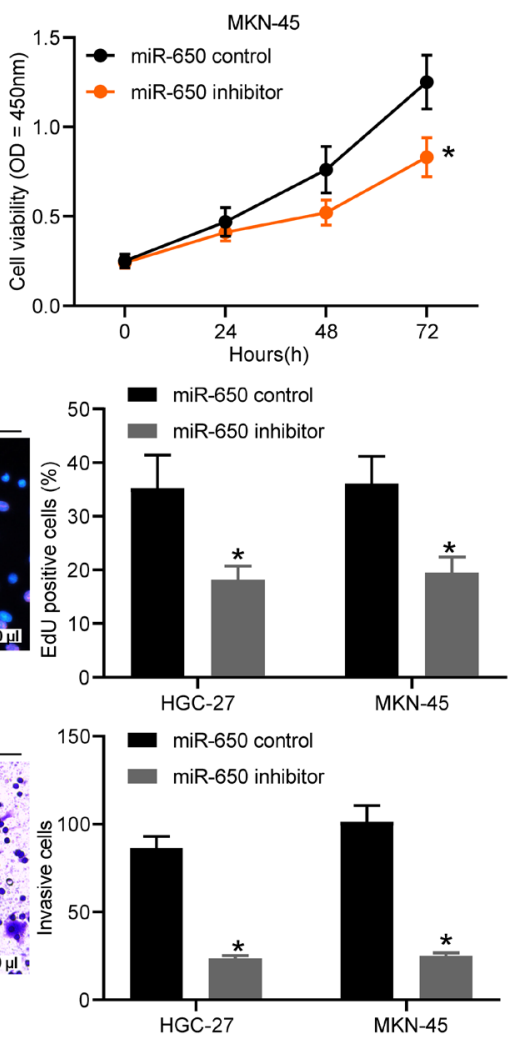

Figure 2. miR-650 inhibitor represses HGC-27 and MKN-45 cell proliferation and invasion. HGC-27 and MKN-45 cells were transfected with the miR-650 inhibitor or miR-650 control. A) RT-qPCR detection of miR-650 expression after transfection; B) CCK-8 detection of HGC-27 and MKN-45 cell proliferation; C) EdU detection of HGC-27 and MKN-45 cell activity; D) Transwell detection of HGC-27 and MKN-45 cell invasion. Differences among three or more groups were tested by two-way ANOVA with comparisons between the two groups using Tukey's post hoc test. Data are displayed as mean \pm SD from three independent experiments. ${ }^{\star} \mathrm{p}<0.05 \mathrm{vs}$. $\mathrm{HP}^{+} \mathrm{GC}$ lines treated with miR-650 control. 
ments, and the declines in miR-650 significantly increased GC cell apoptosis (Figure 3A). Hoechst staining of apoptotic cells also revealed consistent results (Figure 3B). Meanwhile, cell migration was determined by wound healing assay and Transwell assay. We observed the distance of wound healing after $24 \mathrm{~h}$ and found that the cells with the miR-650 knockdown had poorer wound healing and weaker cell migration (Figure 3C). The cells transfected with miR-650 inhibitor were found to be less in the lower chamber (Figure 3D). Our results demonstrated that the downregulation of miR-650 promoted apoptosis of $\mathrm{HP}^{+} \mathrm{GC}$ cells and inhibited cell migration.

PBX1 promotes miR-650 transcription in cells. To find the molecular mechanism of miR-650 in $\mathrm{HP}^{+} \mathrm{GC}$ cells, we performed microarray analysis in $\mathrm{HP}^{+}$and $\mathrm{HP}^{-} \mathrm{GC}$ patients to detect changes in mRNA expression. The heatmap for differentially expressed mRNAs in Figure 4A showed that MDM2 [14], $\beta$-catenin [15], B7-H1 [16], and PBX1 were all significantly increased in the cancer tissues of $\mathrm{HP}^{+} \mathrm{GC}$ patients and may play a role in $\mathrm{HP}^{+} \mathrm{GC}$. PBX1 was revealed as one of the most significantly overexpressed genes in $\mathrm{HP}^{+}$ GC patients. To explore the relationship between PBX1 and miR-650, we first examined PBX1 expression in $\mathrm{HP}^{+}$ patients. We found that PBX1 was significantly upregulated in tumor tissues of $\mathrm{HP}^{+}$patients and positively correlated with miR-650 expression (Figure 4B). PBX1 expression was also evaluated in HP infected GC cells, we also found a significant enhancement in PBX1 mRNA and protein expres-
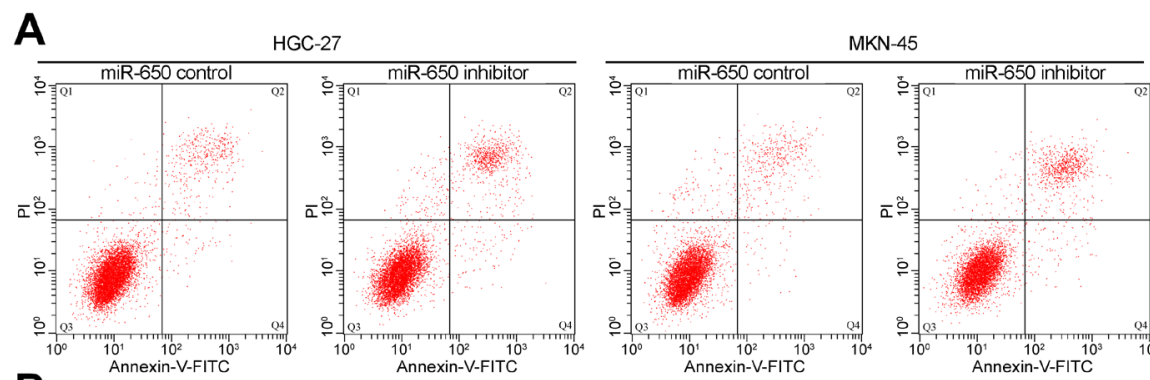

B

HGC-27
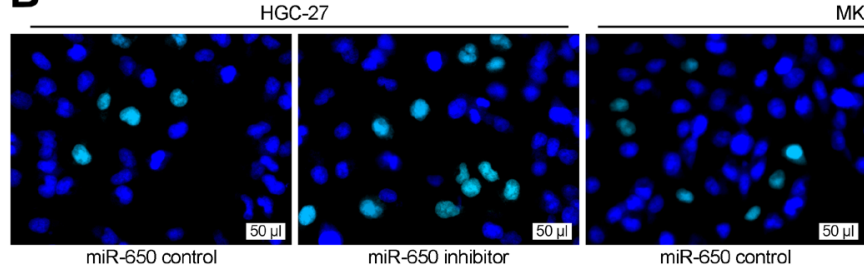

MKN-45
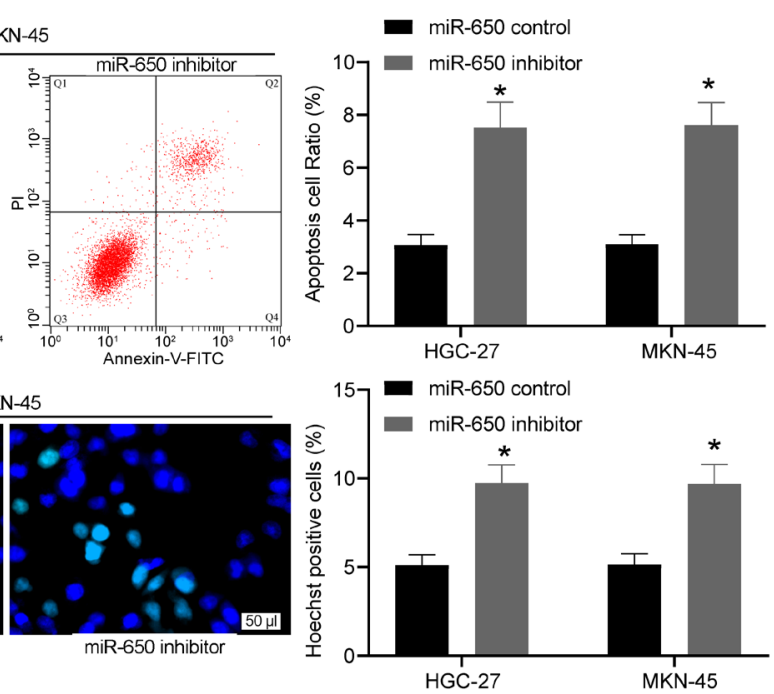

C
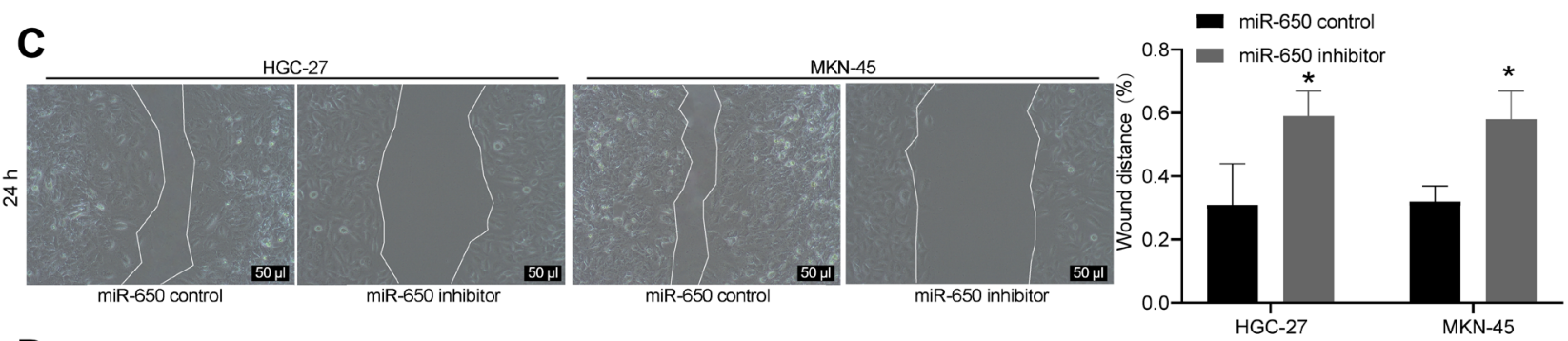

D
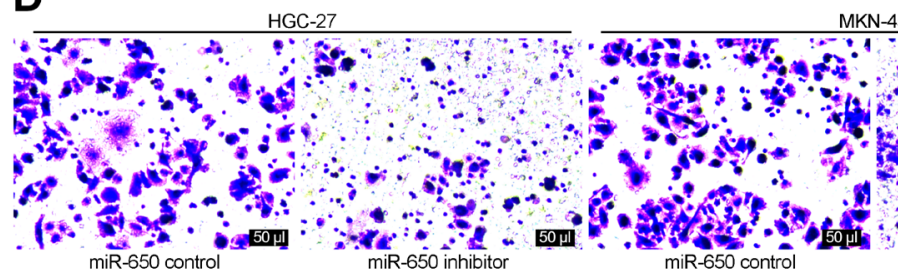

MKN-45
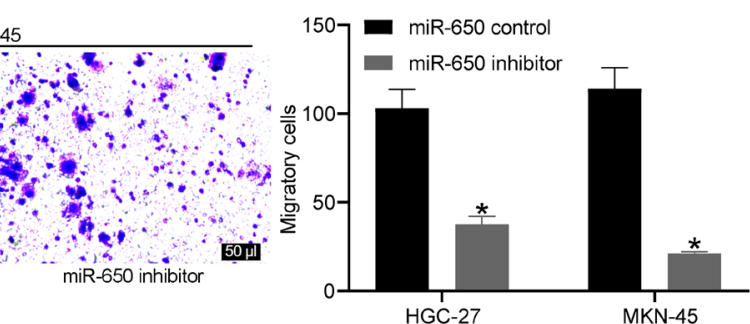

Figure 3. miR-650 inhibitor represses HGC-27 and MKN-45 cell migration, yet promoted apoptosis. A) The assessment of apoptotic HGC-27 and MKN-45 cells by flow cytometric analysis; B) The detection of apoptotic HGC-27 and MKN-45 cell proportion by Hoechst staining; C) HGC-27 and MKN-45 cell wound healing distance by wound healing assay at 24 h; D) HGC-27 and MKN-45 cell migration detected by Transwell experiments. Differences among three or more groups were tested by two-way ANOVA with comparisons between the two groups using Tukey's post hoc test. Data are displayed as the mean \pm SD from three independent experiments. ${ }^{\star} \mathrm{p}<0.05$ vs. $\mathrm{HP}^{+} \mathrm{GC}$ lines treated with miR-650 control. 


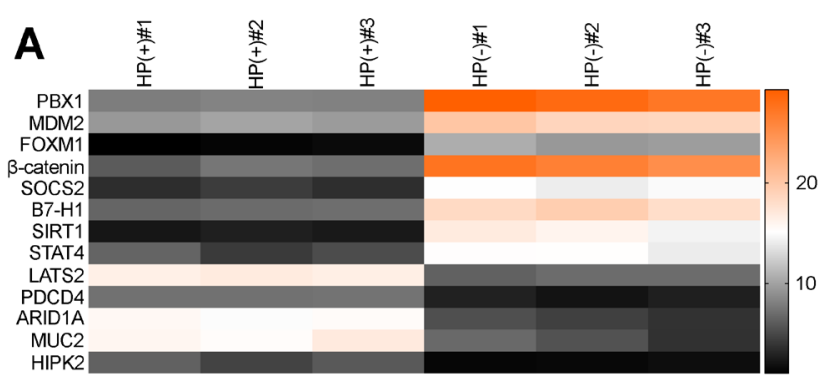

\section{B}
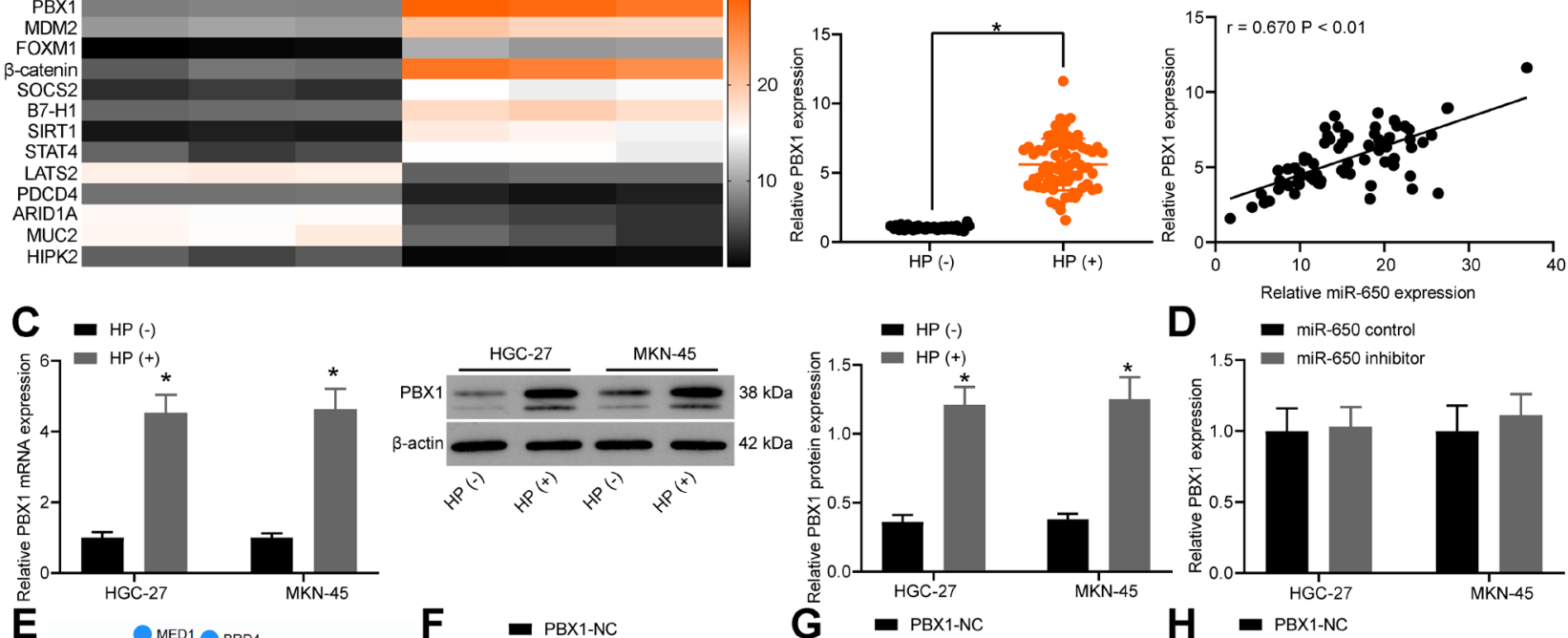

D miR-650 control
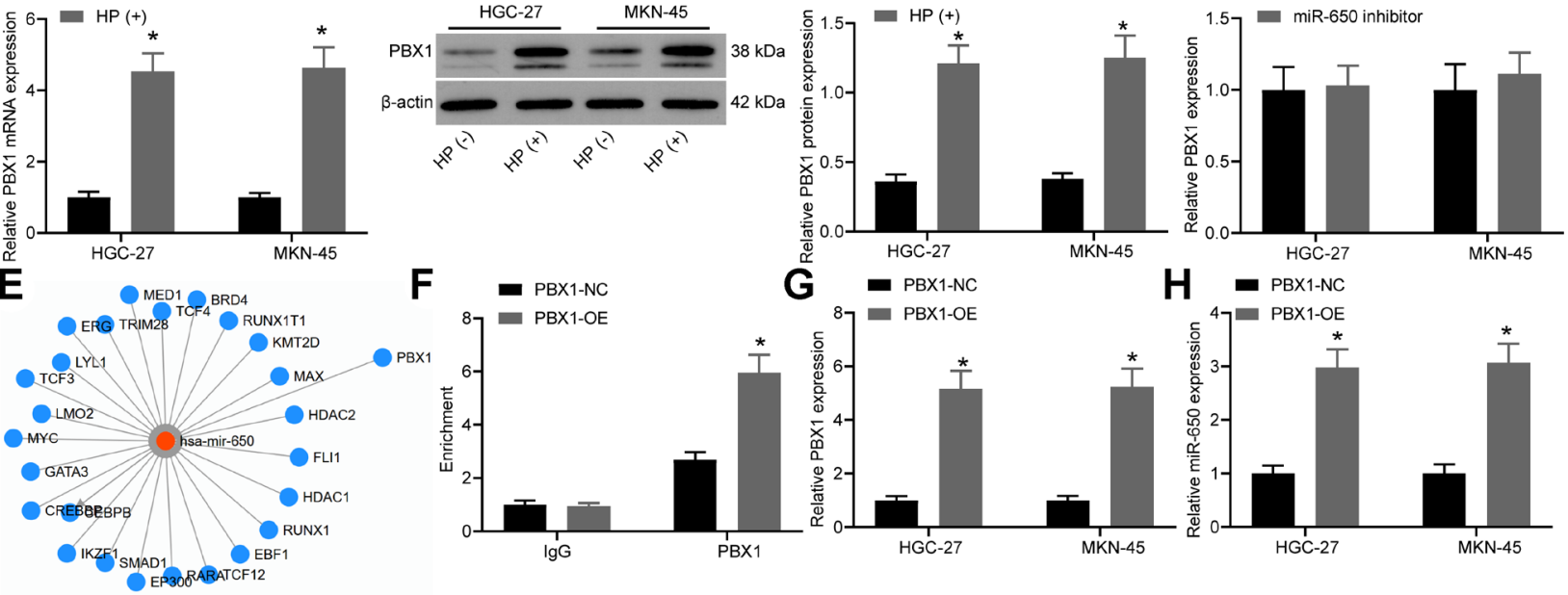

Figure 4. PBX1 is an upstream effector of miR-650. A) The detection of differentially expressed mRNAs in GC tissues by microarray analysis; B) RTqPCR detection of PBX1 expression in $\mathrm{HP}^{+}$GC tissues; C) RT-qPCR and western blot detection of PBX1 expression at the mRNA and protein level in the HGC-27 and MKN-45 cells; D) RT-qPCR assessment of PBX1 expression after downregulation of miR-650 in HGC-27 and MKN-45 cells; E) prediction of transcription factors regulating miR-650; F) enrichment of PBX1 at binding sites after overexpression of PBX1 assessed by ChIP; G) RT-qPCR assessment of PBX1 expression in HGC-27 and MKN-45 cells after upregulation of PBX1; H) RT-qPCR assessment of miR-650 expression in HGC-27 and MKN-45 cells after upregulation of PBX1. Continuous variables between the two groups were compared by unpaired t-test (panel B). Differences among three or more groups were tested by two-way ANOVA with comparisons between the two groups using Tukey's post hoc test (panel C, D, F, G, and $\mathrm{H}$ ). ${ }^{\star} \mathbf{p}<0.05$ vs. HP- GC tissues or cell lines or PBX1 NC treatment.

sion in $\mathrm{HP}^{+}$GC cells (Figure 4C). However, PBX1 did not change significantly with the downregulation of miR-650 (Figure 4D). We found through a bioinformatics website TransmiR v2.0 (http://www.cuilab.cn/transmir) that PBX1 can regulate miR-650 transcription and has a binding site with miR-650 (Figure 4E), which made us wonder if PBX1 was the upstream factor of miR-650. The binding relationship between the PBX1 and miR-650 was detected by ChIP experiments. After overexpression of PBX1, we found that PBX1 was enriched in this site (Figure 4F). Subsequently, we administrated PBX1-OE into GC cells (Figure 4G), and the upregulation of PBX1 showed a significant increase in miR-650 expression (Figure 4H). Thus, we demonstrated that PBX1 also plays a tumor-initiating role in $\mathrm{HP}^{+} \mathrm{GC}$ by enhancing miR-650 transcription.

PBX1 reverses the role of miR-650 inhibitor in GC cells. To further confirm the binding relationship between PBX1 and miR-650, PBX1-OE was delivered into $\mathrm{HP}^{+} \mathrm{GC}$ cells with stable poor expression of miR-650 (Figure 5A). The EdU positive cells after $24 \mathrm{~h}$ of culture significantly increased
(Figure 5B) after overexpression of PBX1. Through the Transwell assay, it was observed that the number of invasive cells increased significantly after the transfection of PBX1-OE (Figure 5C), along with enhanced cell migration (Figure 5D). On the other hand, a significant decrease in apoptosis was observed by flow cytometry (Figure 5E). From these experiments, we found that PBX1 at least partially reversed the inhibitory role of miR-650 downregulation in the biological activity of $\mathrm{HP}^{+} \mathrm{GC}$ cells.

miR-650 mediates the Hippo pathway via LATS2. To explore the downstream factor of miR-650 in cells, we intersected starBase prediction results and mRNA-based microarray analysis and observed that LATS2 was in the intersection (Figure 6A). The binding relationship between miR-650 and LATS2 was verified by dual-luciferase assay (Figure 6B). The expression of LATS2 in $\mathrm{HP}^{+}$tissues was reduced and conversely correlated with miR-650 (Figure 6C). LATS2 expression was also reduced in $\mathrm{HP}^{+} \mathrm{GC}$ cells and promoted in cells with miR-650 knockdown (Figure 6D). Subsequently, we repressed LATS2 expression (Figure $6 \mathrm{E}$ ) in $\mathrm{HP}^{+} \mathrm{GC}$ cells 
A

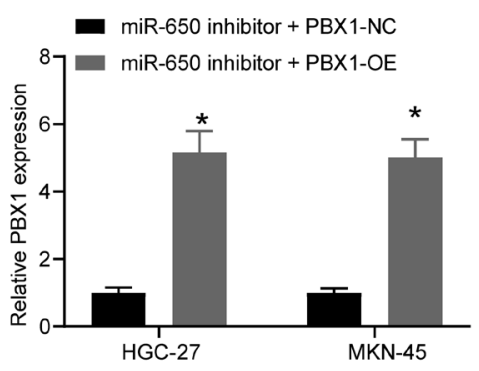

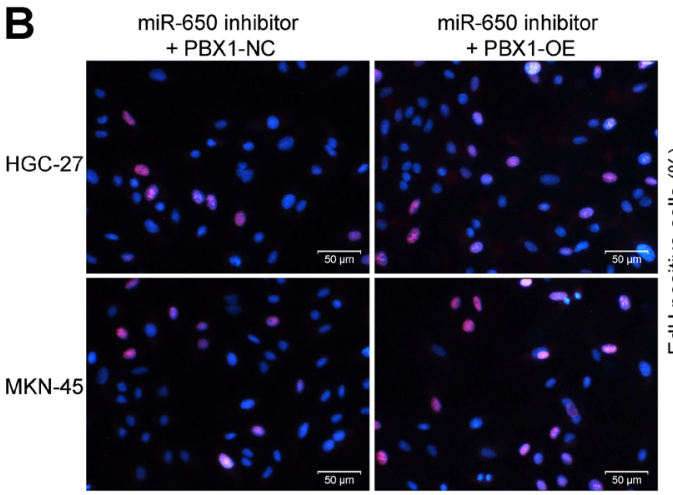

MKN-45
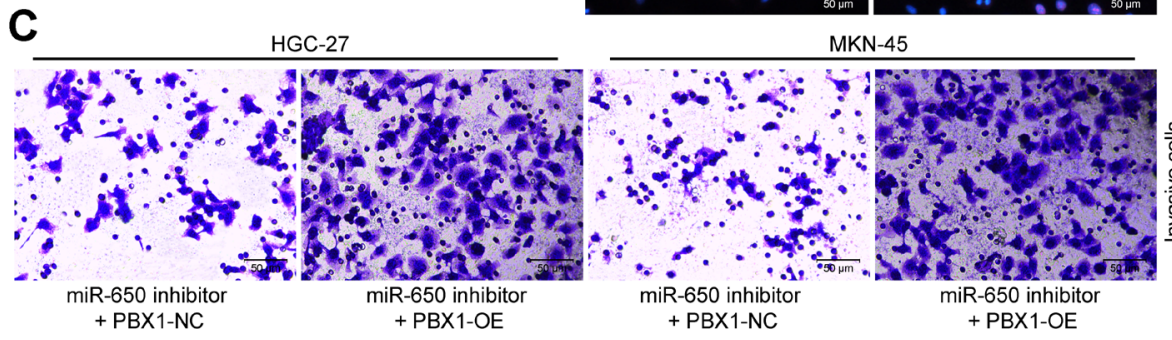

D HGC-27

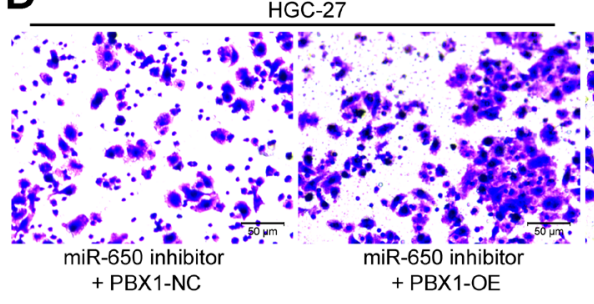

E

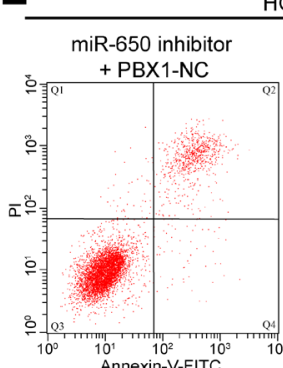

HGC-27

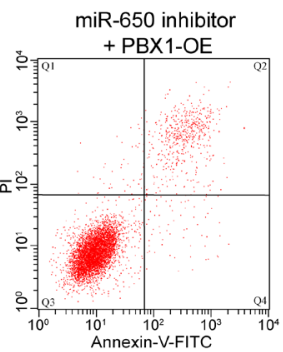

MKN-45

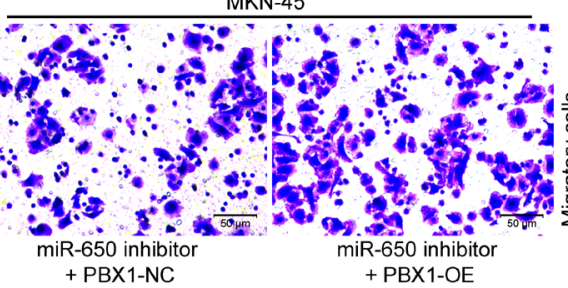

MKN-45

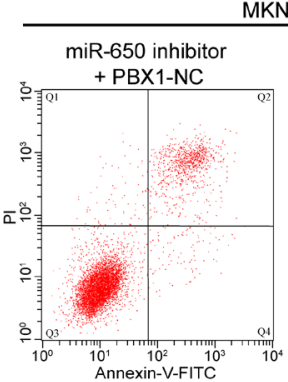

+ PBX1-OE

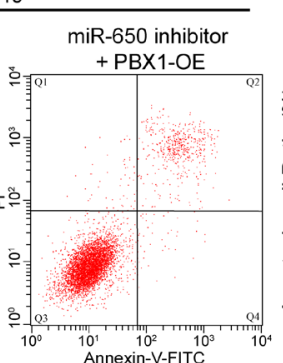

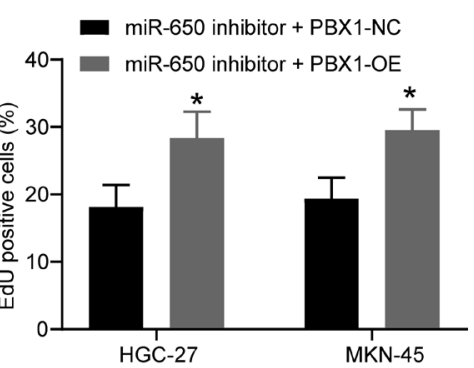

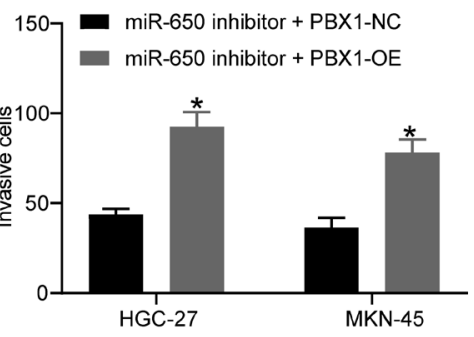

- miR-650 inhibitor + PBX1-NC

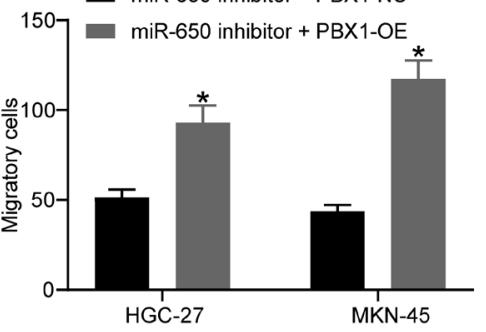

- miR-650 inhibitor + PBX1-NC

10 miR-650 inhibitor + PBX1-OE

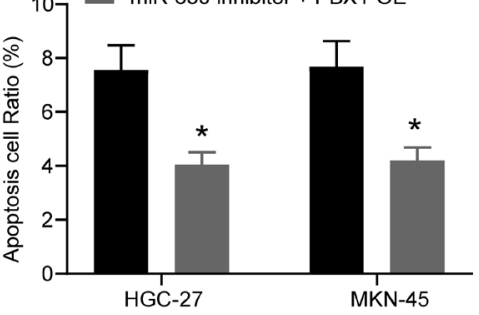

Figure 5. Overexpression of PBX1 reverses the role of miR-650 inhibitor in HGC-27 and MKN-45 cells. HGC-27 and MKN-45 cells were co-transfected with miR-650 inhibitor+PBX1-OE or PBX1-NC. A) RT-qPCR detection of PBX1 in HGC-27 and MKN-45 cells after co-transfection; B) EdU detection of HGC-27 and MKN-45 cell activity; C) Transwell detection of HGC-27 and MKN-45 cell invasion ability; D) Transwell assessment of HGC-27 and MKN-45 cell migration ability; E) detection of HGC-27 and MKN-45 cell apoptosis by flow cytometry. Differences among three or more groups were tested by two-way ANOVA with comparisons between the two groups using Tukey's post hoc test. Data are presented as the mean \pm SD from at least three independent experiments. ${ }^{*} \mathrm{p}<0.05$ vs. $\mathrm{HP}^{+} \mathrm{GC}$ lines treated with miR-650 inhibitor+PBX1-NC.

with the miR-650 inhibitor. The apoptosis level of $\mathrm{HP}^{+} \mathrm{GC}$ cells was decreased (Figure 6F). Since the LATS2 gene is a key gene in the Hippo pathway, we suspected that miR-650 mediated the Hippo pathway. Therefore, we detected the activity of the Hippo pathway in $\mathrm{HP}^{+}$cells by western blot. The Hippo pathway deficit was observed in $\mathrm{HP}^{+} \mathrm{GC}$ cells, and downregulation of miR-650 expedited the Hippo pathway (Figure 6G).

\section{Discussion}

Chronic HP infection is a vital risk factor for distal GC and miRNA dysregulation may contribute to the pathogenesis of HP-induced malignancy transformation [17]. For instance, the expression of miR-223 and miR-17 was upregulated upon HP infection in vivo and in vitro $[12,18]$. miRNAs represent a group of small, non-coding RNAs that 
A

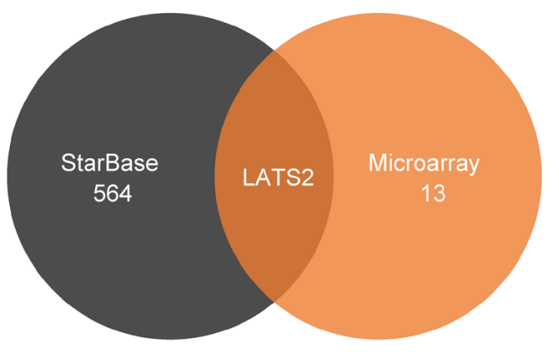

B
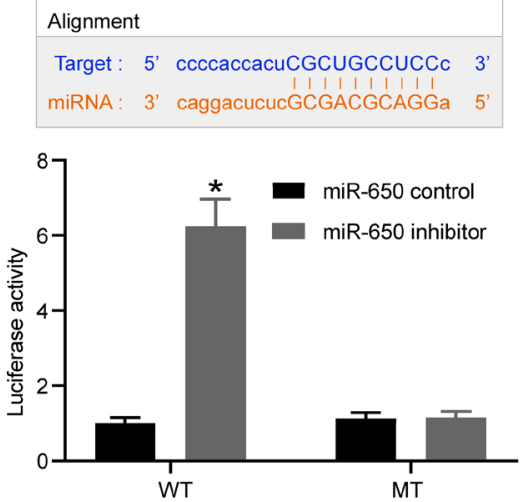

D

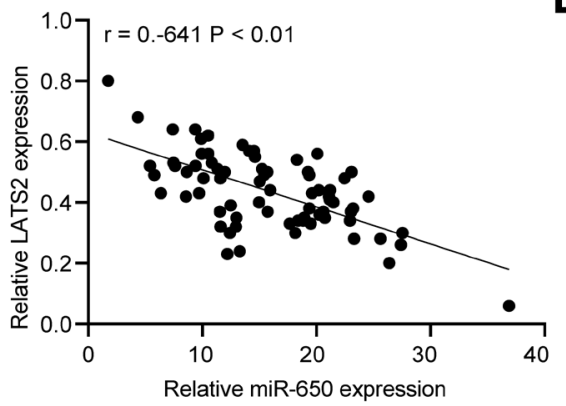

F
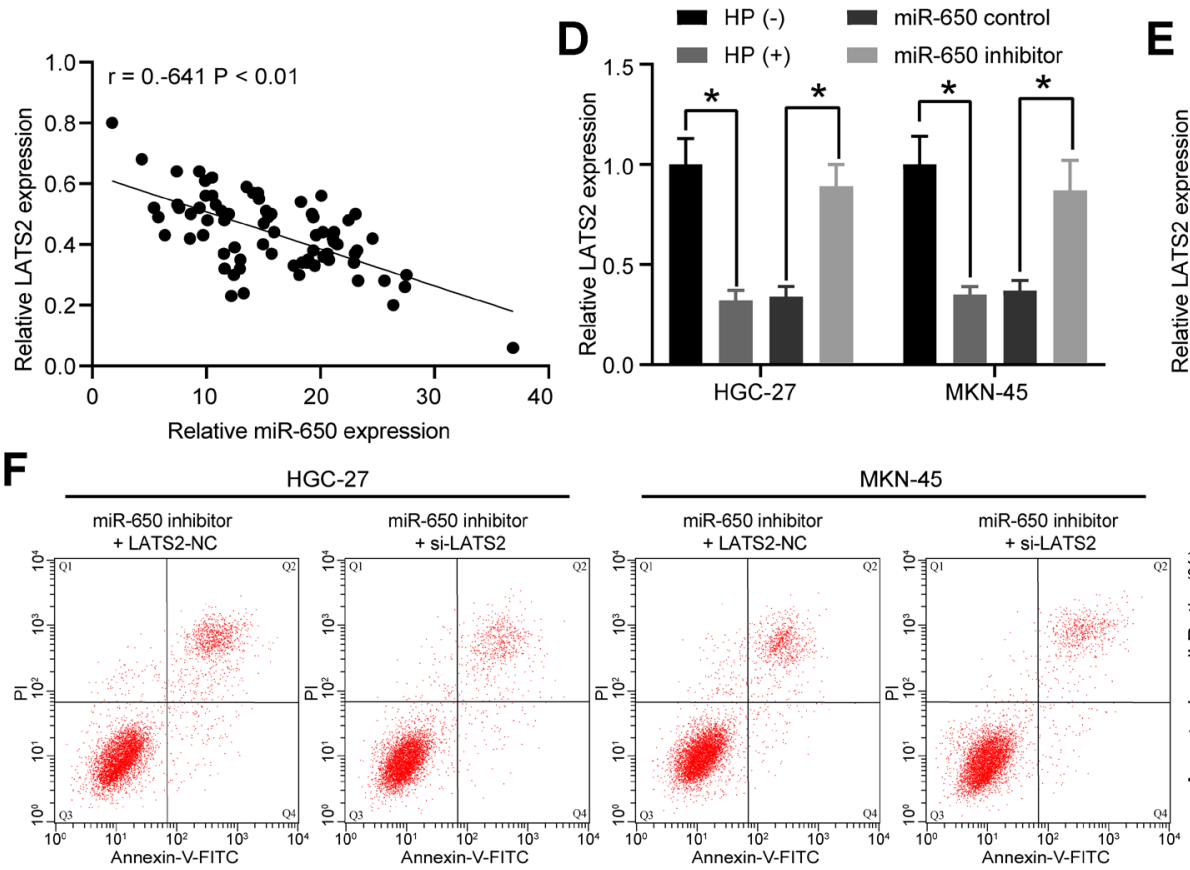

G

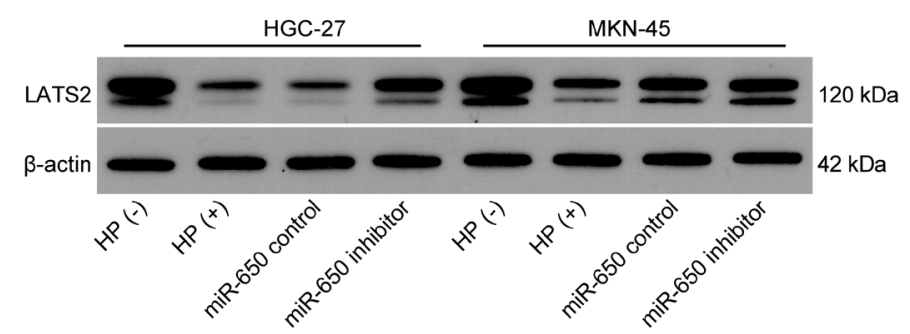

C

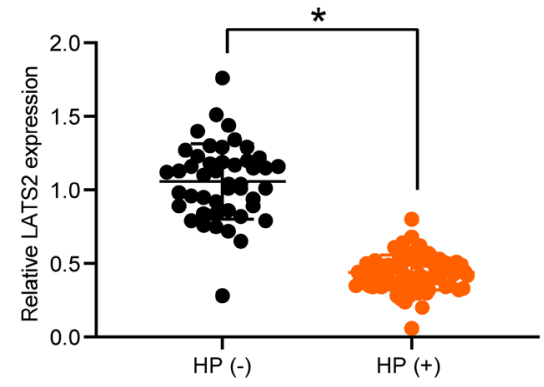

E

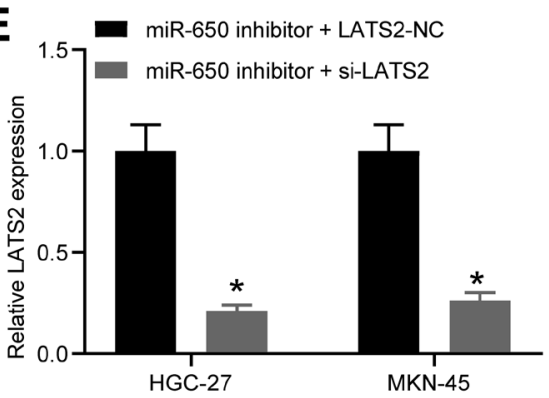

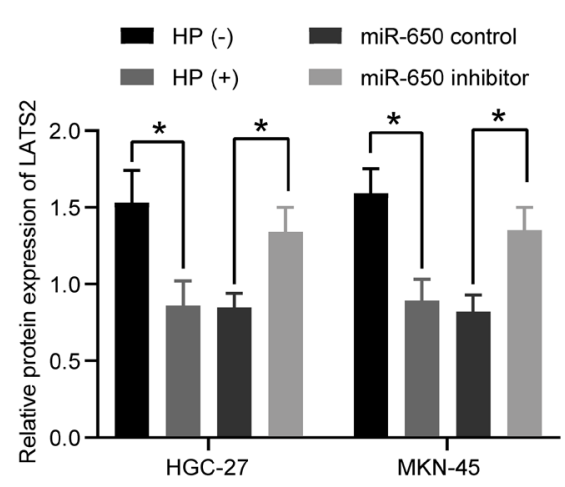

Figure 6. miR-650 mediates the Hippo pathway in $\mathrm{HP}^{+} \mathrm{GC}$ cells. A) The Venn map showing targeting gene of miR-650 in cells; B) targeting relationship between miR-650 and LATS2 detected by dual-luciferase assay; C) RT-qPCR detection of LATS2 expression in tissues of HP ${ }^{+}$and HP- GC patients; D) RT-qPCR detection of LATS2 expression in HGC-27 and MKN-45 cells; E) RT-qPCR detection of LATS2 expression in HGC-27 and MKN-45 cells after inhibition of its expression; F) assessment of apoptotic HGC-27 and MKN-45 cells by flow cytometry after co-transfection of miR-650 inhibitor and si-LATS2; G) western blot detection of LATS2 protein expression in HGC-27 and MKN-45 cells. Continuous variables between the two groups were compared by unpaired t-test (panel C). Differences among three or more groups were tested by two-way ANOVA with comparisons between two groups using Tukey's post hoc test (panel B, D, E, F, and G). ${ }^{*} \mathrm{p}<0.05$ vs. HP- GC tissues, HP- GC cell lines, miR-650 control or miR-650 inhibitor+LATS2-NC treatment. 
participate in post-transcriptional regulation and play an essential role in several steps in carcinogenesis, including cell cycle progression, proliferation, apoptosis, and invasion [19]. The significance of miR-650 has been proposed in the progression of a broad spectrum of tumors [20]. However, the mechanism of miRNAs in GC with HP is much less explored, especially the role of miR-650 in HP-infected GC. Our data from clinical tissue observations and in vitro analyses established the oncogenic role of miR-650 in $\mathrm{HP}^{+}$ GC progression.

This study found significant overexpression of miR-650 in patients with $\mathrm{HP}^{+} \mathrm{GC}$ and GC cells infected with $\mathrm{HP}$ relative to counterparts with $\mathrm{HP}^{-}$, which underlined the importance of HP in elevating the miR-650 expression and consequently manipulating other imperative genes in carcinogenesis of GC. Our prognostic analysis also illustrated that the survival of $\mathrm{HP}^{+}$patients with upregulation of miR-650 was much lower than that of $\mathrm{HP}^{+}$patients with poor expression of miR-650. Similarly, the miR-650 level was notably increased in hepatocellular carcinoma patients and tightly linked to the differentiation level and tumor stage of patients [21]. Later functional experiments illustrated that the miR-650 inhibitor resulted in reduced GC cell proliferation, migration, and invasion, whereas enhanced apoptosis. Similarly, Orlandella et al. proposed that the ectopic expression of miR-650 enhanced cell migration and invasion capacities of anaplastic thyroid cancer, while miR-650 silencing induced an opposite phenotype [22].

Intriguingly, the known HP-induced transcription factors, c-Jun and c-Fos were displayed to be the potential transcription drivers for miR-584 in GC [23]. Therefore, we postulated that miR-650 participated in the development of GC in a similar manner by being regulated by a transcription factor. mRNA-based microarray analysis revealed that PBX1 was a significantly upregulated gene in $\mathrm{HP}^{+} \mathrm{GC}$ patients. Integrated bioinformatics tool and ChIP revealed that PBX1 bound to miR-650. PBX1, located in 1q23, forms a chimeric gene whose protein product impacts cell differentiation arrest as well as other cellular processes [24]. In addition, PBX1 was identified as a transcriptional downregulator of connexin 32 by directly binding to its promoters in HP-related gastric carcinogenesis [25]. While in the current work, we transfected PBX1-OE into $\mathrm{HP}^{+} \mathrm{GC}$ cells along with miR-650 inhibitor, which revealed that PBX1 upregulation rescued the repressive role of miR-650 inhibitor in $\mathrm{HP}^{+} \mathrm{GC}$ cells.

In this study, LATS2 was established by starBase prediction and microarray analysis to be directly targeted by miR-650 in $\mathrm{HP}^{+} \mathrm{GC}$ cells. The direct binding relationship between miR-650 and LATS2 was revealed in hepatocellular carcinoma [26]. LATS2, a tumor suppressor protein, is also a core factor of the Hippo pathway and regulates biological behaviors including cell proliferation, apoptosis, and governance of organ size [27]. Our in vitro evidence supported the published finding, while also illustrated that LATS2 counteracted the effects of miR-650 on GC cell apoptosis. Consistently, the miR-650 overexpression was revealed in lung cancer stem cells, and repression of solute carrier family 34 member 2 lessened the miR-650 silencing-suppressed migration and invasion in lung cancer stem cells [28]. We noted that LATS2 is reduced in $\mathrm{HP}^{+} \mathrm{GC}$ cells, suggesting the Hippo pathway deficit. By contrast, the miR-93-5p inhibitor expedited the Hippo pathway in $\mathrm{HP}^{+} \mathrm{GC}$ cells by elevating LATS2 protein expression [29]. Mechanistically, overexpression of LATS2-AS1-001 has been indicated to induce LATS2 and YAP1 phosphorylation via binding to EZH2 [30]. Still, the detailed mechanism behind the LATS2-mediated Hippo pathway in GC awaits further validation.

In brief, we unveiled miR-650 as a cancer-supporting miRNA in $\mathrm{HP}^{+} \mathrm{GC}$ cells, which exerts critical functions in the proliferation, migration, and invasion capacities of $\mathrm{HP}^{+}$ GC cells. Besides, our findings shed light on the connection between PBX1 and miR-650 and demonstrated that PBX1 meditated expression of miR-650 post-transcriptionally, which then modulated the LATS2-dependent Hippo pathway in GC. PBX1/miR-650/LATS2/Hippo regulatory network may be associated with $\mathrm{HP}^{+} \mathrm{GC}$ cell migration and invasion, thereby providing a possible therapeutic avenue in GC. Even though no effective drug or inhibitor was found yet to target miR-650, PBX1, or LATS2, amlexanox was identified as a potent anti-tumor drug by reducing IKBKE, a negative regulator of the Hippo pathway via controlling LATS1/2 stability [31]. Therefore, amlexanox might be applied in our further in vivo studies for validation.

\section{References}

[1] BRAY F, FERLAY J, SOERJOMATARAM I, SIEGEL RL, TORRE LA et al. Global cancer statistics 2018: GLOBOCAN estimates of incidence and mortality worldwide for 36 cancers in 185 countries. CA Cancer J Clin 2018; 68: 394-424. https://doi.org/10.3322/caac.21492

[2] STRONG VE. Progress in gastric cancer. Updates Surg 2018; 70: 157-159. https://doi.org/10.1007/s13304-018-0543-3

[3] RUSSO AE, STRONG VE. Gastric Cancer Etiology and Management in Asia and the West. Annu Rev Med 2019; 70: $353-$ 367. https://doi.org/10.1146/annurev-med-081117-043436

[4] PLUMMER M, FRANCESCHI S, VIGNAT J, FORMAN D, DE MARTEL C. Global burden of gastric cancer attributable to Helicobacter pylori. Int J Cancer 2015; 136: 487-490. https://doi.org/10.1002/ijc.28999

[5] SVORONOS AA, ENGELMAN DM, SLACK FJ. OncomiR or Tumor Suppressor? The Duplicity of MicroRNAs in Cancer. Cancer Res 2016; 76: 3666-3670. https://doi. org/10.1158/0008-5472.CAN-16-0359

[6] MATSUSHIMA K, ISOMOTO H, INOUE N, NAKAYAMA T, HAYASHI T et al. MicroRNA signatures in Helicobacter pylori-infected gastric mucosa. Int J Cancer 2011; 128: 361370. https://doi.org/10.1002/ijc.25348 
[7] LARIO S, RAMIREZ-LAZARO MJ, ARANSAY AM, LOZANO JJ, MONTSERRAT A et al. microRNA profiling in duodenal ulcer disease caused by Helicobacter pylori infection in a Western population. Clin Microbiol Infect 2012; 18: E273282. https://doi.org/10.1111/j.1469-0691.2012.03849.x

[8] ZHANG X, ZHU W, ZHANG J, HUO S, ZHOU L et al. MicroRNA-650 targets ING4 to promote gastric cancer tumorigenicity. Biochem Biophys Res Commun 2010; 395: 275-280. https://doi.org/10.1016/j.bbrc.2010.04.005

[9] ZUO ZH, YU YP, DING Y, LIU S, MARTIN A et al. Oncogenic Activity of miR-650 in Prostate Cancer Is Mediated by Suppression of CSR1 Expression. Am J Pathol 2015; 185: 1991-1999. https://doi.org/10.1016/j.ajpath.2015.03.015

[10] HU TZ, HUANG LH, XU CX, LIU XM, WANG Y et al. Expressional profiles of transcription factors in the progression of Helicobacter pylori-associated gastric carcinoma based on protein/DNA array analysis. Med Oncol 2015; 32: 265. https://doi.org/10.1007/s12032-015-0711-y

[11] YE Y, ZHUANG J, WANG G, HE S, NI J et al. microRNA-605 promotes cell proliferation, migration and invasion in non-small cell lung cancer by directly targeting LATS2. Exp Ther Med 2017; 14: 867-873. https://doi.org/10.3892/ etm.2017.4538

[12] MA L, CHEN Y, ZHANG B, LIU G. Increased microRNA-223 in Helicobacter pylori-associated gastric cancer contributed to cancer cell proliferation and migration. Biosci Biotechnol Biochem 2014; 78: 602-608. https://doi.org/10.1 080/09168451.2014.895661

[13] XIAO T, JIE Z. MiR-21 Promotes the Invasion and Metastasis of Gastric Cancer Cells by Activating Epithelial-Mesenchymal Transition. Eur Surg Res 2019; 60: 208-218. https:// doi.org/10.1159/000504133

[14] LV BB, MA RR, CHEN X, ZHANG GH, SONG L et al. E2F1activated SPIN1 promotes tumor growth via a MDM2p21-E2F1 feedback loop in gastric cancer. Mol Oncol 2020. https://doi.org/10.1002/1878-0261.12778

[15] ZHANGY,XUJ, FU H, WEIZ, YANGD etal. UBE3C promotes proliferation and inhibits apoptosis by activating the betacatenin signaling via degradation of AXIN1 in gastric cancer. Carcinogenesis 2020. https://doi.org/10.1093/carcin/bgaa098

[16] LINA TT, GONZALEZ J, PINCHUK IV, BESWICK EJ, REYES VE. Helicobacter pylori elicits $\mathrm{B} 7 \mathrm{H} 3$ expression on gastric epithelial cells: Implications in local T cell regulation and subset development during infection. Clin Oncol Res 2019; 2. https://doi.org/10.31487/j.cor.2019.05.05

[17] CHEN P, GUO H, WU X, LI J, DUAN X et al. Epigenetic silencing of microRNA-204 by Helicobacter pylori augments the NF-kappaB signaling pathway in gastric cancer development and progression. Carcinogenesis 2020; 41: 430-441. https://doi.org/10.1093/carcin/bgz143

[18] KHAYAM N, NEJAD HR, ASHRAFI F, ABOLHASSANI M. Expression Profile of miRNA-17-3p and miRNA-17-5p Genes in Gastric Cancer Patients with Helicobacter pylori Infection. J Gastrointest Cancer 2020. https://doi.org/10.1007/ s12029-019-00319-5

[19] NOTO JM, PEEK RM. The role of microRNAs in Helicobacter pylori pathogenesis and gastric carcinogenesis. Front Cell Infect Microbiol 2011; 1: 21. https://doi.org/10.3389/ fcimb.2011.00021
[20] FAROOQI AA, QURESHI MZ, COSKUNPINAR E, NAQVI SK, YAYLIM I et al. MiR-421, miR-155 and miR-650: emerging trends of regulation of cancer and apoptosis. Asian Pac J Cancer Prev 2014; 15: 1909-1912. https://doi.org/10.7314/ apjcp.2014.15.5.1909

[21] ZENG ZL, LI FJ, GAO F, SUN DS, YAO L. Upregulation of miR-650 is correlated with down-regulation of ING4 and progression of hepatocellular carcinoma. J Surg Oncol 2013; 107: 105-110. https://doi.org/10.1002/jso.23210

[22] ORLANDELLA FM, MARINIELLO RM, IERVOLINO PLC, IMPERLINI E, MANDOLA A et al. miR-650 promotes motility of anaplastic thyroid cancer cells by targeting PPP2CA. Endocrine 2019; 65: 582-594. https://doi.org/10.1007/ s12020-019-01910-3

[23] EBRAHIMI GHAHNAVIEH L, TABATABAEIAN $\mathrm{H}$, EBRAHIMI GHAHNAVIEH Z, HONARDOOST MA, AZADEH M et al. Fluctuating expression of miR-584 in primary and high-grade gastric cancer. BMC Cancer 2020; 20: 621. https://doi.org/10.1186/s12885-020-07116-5

[24] ORGANISTA-NAVA J, GOMEZ-GOMEZ Y, ILLADESAGUIAR B, LEYVA-VAZQUEZ MA. Regulation of the miRNA expression by TEL/AML1, BCR/ABL, MLL/AF4 and TCF3/PBX1 oncoproteins in acute lymphoblastic leukemia (Review). Oncol Rep 2016; 36: 1226-1232. https://doi. org/10.3892/or.2016.4948

[25] LIU XM, XU CX, ZHANG LF, HUANG LH, HU TZ et al. PBX1 attributes as a determinant of connexin 32 downregulation in Helicobacter pylori-related gastric carcinogenesis. World J Gastroenterol 2017; 23: 5345-5355. https://doi. org/10.3748/wjg.v23.i29.5345

[26] HAN LL, YIN XR, ZHANG SQ. miR-650 Promotes the Metastasis and Epithelial-Mesenchymal Transition of Hepatocellular Carcinoma by Directly Inhibiting LATS2 Expression. Cell Physiol Biochem 2018; 51: 1179-1192. https://doi. org/10.1159/000495495

[27] MA LC, TIAN XY, GAO F, DONG WJ, DANG T et al. Association analysis between SNPs in LATS1 and LATS2 and non-cardia gastric cancer. BMC Gastroenterol 2020; 20: 155. https://doi.org/10.1186/s12876-020-01250-x

[28] ZHAO Y, ZHU Z, SHI S, WANG J, LI N. Long non-coding RNA MEG3 regulates migration and invasion of lung cancer stem cells via miR-650/SLC34A2 axis. Biomed Pharmacother 2019; 120: 109457. https://doi.org/10.1016/j.biopha.2019.109457

[29] LI L, ZHAO J, HUANG S, WANG Y, ZHU L et al. MiR-93$5 \mathrm{p}$ promotes gastric cancer-cell progression via inactivation of the Hippo signaling pathway. Gene 2018; 641: 240-247. https://doi.org/10.1016/j.gene.2017.09.071

[30] SUN D, WANG Y, WANG H, XIN Y. The novel long noncoding RNA LATS2-AS1-001 inhibits gastric cancer progression by regulating the LATS2/YAP1 signaling pathway via binding to EZH2. Cancer Cell Int 2020; 20: 204. https:// doi.org/10.1186/s12935-020-01285-w

[31] LIU Y, LU J, ZHANG Z, ZHU L, DONG S et al. Amlexanox, a selective inhibitor of IKBKE, generates anti-tumoral effects by disrupting the Hippo pathway in human glioblastoma cell lines. Cell Death Dis 2017; 8: e3022. https://doi.org/10.1038/ cddis.2017.396 